\title{
INTERCULTURAL BLENDED DESIGN CONSIDERATIONS: A CASE STUDY OF A NORDIC-BALTIC COURSE IN AUTISM INTERVENTION
}

\author{
Annika Käck_[annika.kack@su.se],Lise Roll-Pettersson [Lise.roll-pettersson@specped.su.se], \\ Stockholm University, Sweden, ShablaS Alai-Rosales [Srosales@unt.edu], University of North Texas, \\ United States of America, Kari Hoium [kari.hoium@bioa.no], Oslo and Akershus University College, Norway, \\ Sirk.kuMännik.kö-Barbutiu [sirke.u@dsv.su.se],UnoGH Fors [Uno@dsv.su.se],Stockholm University, \\ Sweden [http://dsv.su.se/en/]
}

\begin{abstract}
Specialized educational programs previously unavailable to many students are now accessible to students spread throughout the world. In particular, this globalization presents new opportunities and challenges for universities educating professionals in the field of autism treatment. The aim of the present case study is to analyse the experiences of students who participated in an intercultural graduate level blended learning course in applied behaviour analysis with an autism focus. Students were enrolled in universities in four Nordic-Baltic countries. Country based focus group interviews and surveys were used to explore student's experiences and perceptions. Results indicate that access to expertise and interacting with other cultures were noted to positively affect learning experience. Risk for cultural divide due to discrepancies in technology, differing pedagogical traditions, and understanding of English were also reported. Implications regarding the potential risks and benefits inherent in intercultural blended learning courses are discussed and suggestions are offered for enhancing the success of such courses.
\end{abstract}

Keywords: applied behaviour analysis, intercultural, blended learning, higher education, multiinstitutional

\section{Introduction}

The acceleration of Information and Communication Technologies (ICT) combined with globalization and the movement toward "higher education for all," has created learning environments in which information previously unavailable has become accessible to a much broader range of students. Blended learning (BL), which combines web-based learning with faceto-face interactions, has the potential to synchronize students with instructors who have specific expertise spread throughout the world. Blended learning allows tailoring of instruction to accommodate students who reside in locations that lack access to a specific content (Bonk \& Graham, 2006).

\section{Demand for advanced training in autism treatment}

Dramatic increases in autism spectrum disorder (ASD) prevalence are reported, with estimates as high as 1 per 88 (Center for Disease Control and Prevention, 2012). This increased prevalence is worldwide and, regardless of culture, individuals with ASD and present varying degrees of cognitive impairment and display a continuum of verbal, social and communicative impairments 
affecting all areas of life (American Psychiatric Association, 2000). The severe nature of the disorder requires that, to be effective, professionals working with these individuals have a thorough knowledge of evidence-based practice and highly developed clinical skills (Yell et al., 2005; Green, 2010; Odom et al., 2010; National Autism Center, 2009; Behavior Analysis Certification Board, 2014). Specifically, in-depth theoretical and practical knowledge of the principles and procedures of Applied Behaviour Analysis (ABA) are required (Odom et al. 2010; National Autism Center, 2009; Ala'i-Rosales et al., 2010; Behavior Analysis Certification Board, 2014). ABA integrates science, practice and ethics (Baer et al., 1968) and is considered the foundation of an autism intervention curriculum (Sulzer-Azaroff et al., 2008).

Reports indicate that a limited number of institutions of higher education (HEI) are preparing professionals to meet the therapeutic demand for the increasing number of children diagnosed with autism. Worldwide, it is clear that the lack of higher education training programs has resulted in a shortage of sufficiently skilled professionals (cf; Scheuermann, et al., 2003; Simpson et al., 2011; Grey et al., 2005) In order to support a basic level of competence among practitioners, The Behavior Analysis Certification Board (BACB) ${ }^{\mathrm{TM}}$ delineated basic theoretical, clinical, and professional skills to be included in approved university coursework. The number of universities offering coursework meeting these requirements has been slowly increasing (Weiss \& Shook, 2010). Due to the extreme shortage of advanced professionals available to provide university instruction, many of these programs involve distance or blended education designs (Roll-Petterson et al., 2010). In the first published evaluation of a blended ABA program with a focus on autism, Roll-Pettersson and Alai-Rosales, (2009) designed and implemented a blended bi-institutional course for graduate professionals in Sweden. The blended elements consisted of videoconferencing, email, an e-learning platform, previously recorded lectures and onsite meetings with simulation activities, group projects, and case activities. The project was a collaboration between two universities, the University of North Texas (USA) and the University of Stockholm (Sweden) with students living in one cultural context. One professor with expertise in early intervention was based in Stockholm with the students and the other professor with expertise in Applied Behaviour Analysis and autism interventions was based in Texas. Students involved in the course reported high satisfaction with all aspects of the course (Roll-Pettersson \& Alai-Rosales, 2009).

\section{Pedagogical considerations}

Researchers in distance education underscore the importance of effective higher education teaching and the need for technology to be adapted to pedagogical consideration and not vice versa (cf. Holley \& Oliver, 2010; Pombo et al., 2010; Stacey \& Gerbic, 2007). Pedagogical requirements with regard to type of conceptual and clinical skills required in autism intervention involve high levels of engagement interaction, and feedback. Research-based synthesis has found that within these contexts, adult learners benefit from a guided design approach that includes student problem solving, small group teaching, and incorporation of real world elements in course content, active student participation and strategies to promote self-directed inquiry (Trivette et al., 2009). "Social presence" and being part of a learning community are important aspects found to strengthen higher order learning outcomes and course satisfaction (Palloff \& Pratt, 2007). Palloff and Pratt highlight the importance of integrating social interaction in online learning activities and maintain that high degrees of social interaction embedded in courses tend to increase student's perception of social presence and engagement (2007).

In sum, highly interactive and socially engaging activities are important for both autism intervention instruction as well as distance education. Related to this are implications for pedagogy that involves collaborative and reflective interactions between students and the subject matter. Engeström (1987) describes the collective and innovative knowledge building process as 
"expansive learning" when learning a particular subject transforms from the experiences of an isolated individual into a collective or a network of learners. This approach can be applied in online distance learning by facilitating collaborative assignments that bring learners and their differing experiences, competences and skills together.

\section{Cultural considerations}

Like many educational programs that rely on limited supply of global expertise, blended education programs in autism may involve the participation of instructors from several different cultures. This requires some degree of cultural competence. Culture is defined as socially constructed attitudes, norms, values, goals, and practices in a variety of contexts, including social, and academic. Though there is no single agreed upon definition of intercultural competence or how it evolves, it involves the ability to interact effectively and appropriately with people from other cultures (Perry \& Southwell, 2011). On a personal level aspects affecting intercultural competence include cognitive, affective, and behavioural dimensions. The cognitive dimension includes understanding one's own culture and other cultures including similarities and differences across cultures (2011). However, as Perry et al point out, accumulating knowledge and facts about culture is not sufficient, positive affective dimensions such as empathy, curiosity, and respect as well as verbal and non-verbal behavioural components are also necessary. A challenge for intercultural course designers is that there is a lack of clear-cut reliable criteria for defining or measuring components that effect intercultural sensitivity/competence (Perry \& Southwell, 2011). With increasing globalization, this has become a general issue within higher education institutions, whether campus based or on line. In fact, specific learning objectives are being proposed to address the growing need for cultural competency (Karlburg, 2010).

A number of studies examine cultural issues in blended or online learning contexts. These studies involve cultural mixtures in which students are educated in/or by a non-primary culture. For example Cronjé (2009) examined barriers in a two-year BL master's program and observed that when working across radically different cultures instructors need to address the impact of culturally sensitive assessment systems, implement flexible course organization, and adapt pedagogical methods to students' prerequisites which include the use of English as a second language. In a cross-cultural study Zhu, Valcke, and Schellens (2009) compared the experiences and perceptions of Chinese students with Flemish students in an online course. The students had no interaction with one another. The study revealed that the Chinese group adopted relatively negative views of the socio-constructivist e-learning environment while the Flemish students became more positive. This suggests that, given personal and cultural experience, students can have polarized responses to the same instructions. Durkin (2008), however, found that students from China pursuing Masters Degrees in Britain preferred to synchronize and blend elements from both cultures. Rapoport (2006) argues against assuming that all countries perceive western teaching methods as superior and maintains that educational practices are determined by broader cultural conversations. Muntean, Calinici, Tigan and Fors (2013) examined the importance of culture by testing the viability of "virtual patients" in a Romanian medical school using cases developed in the UK, USA or Romania. Their results revealed that culture had the strongest statistical effect on students' ability to reach a correct diagnosis and therapeutic plan. Clearly, the culture of the course instructors and students interacts in complex ways. Lacking, to our knowledge, are descriptions of mixed culture courses involving more than two cultures that jointly collaborate in course design and in which cultural differences are more nuanced.

In summary, as the number of intercultural courses is increasing, it is becoming more relevant for instructors in higher education to understand and take into consideration the dynamics of intercultural teaching and learning environments. What challenges do instructors face when the student group has varying cultural, social, and historical backgrounds? How should course European Journal of Open, Distance and e-Learning - Vol. 17 / No. 1 
designers relate to the differing traditions of knowledge and practices? Particularly interesting are blended learning environments where the teaching and learning are further challenged by variations in technological commodities.

This paper presents a multi-institutional case study with the aim to gain a deeper understanding of how students respond to course content and blended learning activities. We had several research objectives. First, we were interested to know if the students felt they benefitted from participation in the course: Did they increase knowledge related to autism intervention? Second, we wanted to understand their views of the blended learning format. Third, we asked if participation in this course would contribute to increasing student's intercultural awareness. Fourth, we wanted to identify challenges that would inform and shape future implementation of similar courses. Finally, using the results from this study as well as the extant literature we sought to formulate a design template for future multi-institutional intercultural blended learning courses.

\section{Context of study}

This study extends previous research using blended learning and bi-institutional collaboration (Roll-Pettersson \& Alai-Rosales, 2009). Due to the paucity of expertise in ABA and autism intervention within the Nordic-Baltic region, higher education institutions with faculty knowledgeable or interested in the field were contacted by the second author and invited to participate in the project. A prerequisite for institutional participation was instructional materials (literature, lectures, and assignments) be delivered in English.

\section{Participating HEI}

This case study includes four different higher education institutions (HEI) within the NordicBaltic region. Each HEI was in a different country. In total, 19 students completed the first section of the course; three did not attend the onsite section. Thus, 16 students, four males and 12 females, completed both sections of the course. Stockholm University (Sweden) was designated coordinating HEI and the participating representatives as onsite facilitators.

- Country one: Five students and one on-site facilitator, who was Adjunct Professor in Special Education and was also cognitive behavioural therapist. Students were enrolled in a master program in Special Education.

- Country two: Two students, one on-site facilitator, who was Professor in behavioural psychology. Students were enrolled in a master program in behavioural psychology.

- Country three: Five students and one onsite- facilitator, who was an Associate Professor in allied health services with a focus on disabilities. Students were enrolled in a master program in allied health.

- Country four: Four students and one onsite- facilitator, who was an Associate Professor in special education and had studied behaviour analysis. Students were enrolled in a certificate program in special education.

With the exception of country three the majority of the students were fluent in English. This course was the first experience country one, three and four had in behaviour analysis and autism intervention. In all countries this particular course was elective within the program. All countries were democracies and parliamentary however one was also described as a constitutional monarchy. 


\section{Ethical considerations}

Due to the intercultural nature of this study specific ethical considerations concerning identification of countries have been taken into account, and we have chosen not to disclose either the name of the country or HEI, with the exception of Stockholm University. Confidentiality is especially important as some information obtained through the focus group interviews might be interpreted as culturally sensitive. As Reyen (2012) points out researchers working in intercultural projects need to be aware and respectful of potential harm that can be caused through information disclosure obtained from interviewees. By not disclosing names of countries or HEI we are able to highlight sensitive issues of potential importance for future intercultural blended learning projects.

\section{Pedagogical design}

Representatives from each of the HEI met for two days, and reached a consensus on content, intended learning outcomes, guided design elements, pedagogical methods, sharing of responsibilities, and blended-learning elements. The parameters considered in the pedagogical design included: the disciplinary requirements (Behavior Analysis Certification Board, 2014), technological capability across the HEI settings, faculty expertise in ABA and autism, and disciplinary considerations in assessment of blended learning outcomes (Roll-Petterson et al., 2010).

The course had two distinct blended sections, one ICT and the other onsite. The ICT section consisted of videoconference lectures and discussions, a streamed lecture, Skype ${ }^{\mathrm{TM}}$ meetings, video clips, and email correspondence. Videoconference lectures were given in a studio and students participated in the lectures from studios within their HEI (with the exception of the students in country three who participated via Skype). Lecturers were persons with expertise within a specific area of relevance to course content. Time was allotted for students to ask the lecturer direct questions and engage in discussions with other participants. It was designed this way in order to enhance understanding of content matter as well as to encourage social interaction. Videoconferencing was chosen as the preferred medium for lectures because it has proven to be user friendly and requires minimal technical support (Roll-Pettersson \& AlaiRosales, 2009; Mavroidis et al, 2013). To expand lectures and enhance social interaction between cultures, students were also paired with a student from another culture to discuss lecture content and jointly write reaction papers via Skype. The papers were then sent via e-mail to both the onsite facilitator and the course coordinator for evaluation and feedback.

The onsite section of the course took place in country three following the videoconferencing lectures. Face to face activities consisted of clinical simulations, group presentations and lectures. Final grades were based on the completion of lecture reaction papers, case reviews, and exams. The case activity was a country based group assignment. Students were provided with a case describing a young child with distinctive autism spectrum symptoms they were instructed to describe the diagnostic process and therapeutic supports available in their countries. They then presented the case process to the entire group.

\section{Data collection}

The data collected in this case study was completed through questionnaires and country based focus group interviews, providing both a general overview of student perceptions and experiences as well as more in-depth information on how students perceived course participation, content, and pedagogical practices. 


\section{Questionnaires}

In order to collect data about students' perceptions and experiences of the course two questionnaires were designed. This was a collaborative effort between course instructors and the Stockholm Pedagogical Centre at Stockholm University. The questionnaires were in English. Student responses were made on a Likert-type format with five alternatives; $1=$ never/totally disagree, $3=$ neither never or always / neither disagree or agree, to $5=$ always/totally agree. The first questionnaire was completed in online at the end of the computer-mediated section concerning technical, content and cultural aspects. The second questionnaire was administered at the offset of the onsite section and covered content and methods, learning climate, and cultural aspects as well as general perceptions concerning the course in its entirety.

\section{Country-based focus group interviews}

In order to obtain a deeper picture and complement data collected through questionnaires, four semi-structured country-based focus-group interviews were conducted by one of the authors with experience as a focus- group moderator. This author had no other affiliation with the course or the students. Focus groups were chosen because they are especially useful for exploring how a group of individuals with some degree of common identity experience a particular situation (Stewart et al., 2007). They took place at the end of the onsite section and were recorded on a digital voice recorder. Interviews lasted approximately 40 minutes.

\section{Data analysis}

Data analysis of the questionnaires was calculated using standard deviation and mean values, however group comparisons and correlation analysis were not conducted due to the small sample size. Analysis of the focus group interviews was inspired by a grounded theory approach (Corbin $\&$ Strauss, 2008). We used the adductive analysis process described by Dey (2004) in which previously conducted research influenced the interpretation of data. Thus, the interpretation was contextual and will therefore hopefully provide practical guidelines to practitioners within similar settings/contexts, (i.e. considerations of importance when designing and implementing intercultural blended learning courses). The analysis process consisted of several steps. First, interviews were transcribed verbatim, and read separately by two of the authors, who made lineby-line notes consisting of interpretative memos, concepts, and emerging categories. The authors then met and compared notes; discussed emerging categories based on the research questions, and used the constant comparative method to uncover conditions, interactions and consequences affecting participants' experiences and perceptions. This led to some categories being merged, omitted, or reconceptualised. Citations from interviews were chosen based on their representativeness in relation to each category.

\section{Results}

\section{Questionnaire concerning ICT section of course}

Students were satisfied with technical aspects of the course (SD 0.8; M 4.4). The majority agreed that interactive video conferencing could be used more often in higher education (SD 0.9; M 4.3) and that the course has provided them with opportunities to participate in lectures and subject matter they would not have had at their home university/college (SD 0.6; M 4.1). Lowest ratings pertained to statements concerning language and culture. Participation for some students was limited by having to interact and speak in English (SD1.1; M 3,8) the intercultural Skype discussions for enhancing understanding of topic had the lowest agreement rating (SD1.1; M 3,4) 
followed by students perceiving they had obtained deeper understanding of participating countries (SD 1.0; M 3,7).

\section{Onsite section and perceptions of total learning environment}

Responses indicate that students perceived the learning climate as open and positive (SD 0.4; M 4.8) and that, through participation in the course they obtained a greater understanding and interest in applied behaviour analysis (SD 0.4; M 4.5). Through participation in the onsite section they developed their cultural competence (SD 0.6; M 4.0). Students tended to not to perceive that they were inhibited actively participate in the classroom discussions due to having to speak English (SD 0.5; M 1.5). Practically all students rated that mixing cultures in blended learning courses should be used more often in HE courses (SD 0.4; M 4.8).

\section{Country-based focus group interviews}

Analysis from the country-based focus group interviews revealed four core categories. The core categories are; 1) technology and social presence; 2) integrating perspectives and importance of content; 3) pedagogical considerations; and 4) the world becomes more open. A summary of each theme with representative comments is included here. The English in some of the citations has been slightly changed for readability purposes.

\section{Technology and its effect on social presence}

As part of the course used ICT it was important to gain a deeper understanding of students' perception of the effects of technology. Technology or lack of technology came to play a central role in how the students perceived each other.

The feeling of social presence, being in the same social space, was recognized by students as important. The students from countries one, two and four could see each other on the same screen but the students from country three did not have access to video conference technology. As the ICT section of the course progressed so did an exclusionary process. An unexpected finding was that "cultural divides" were unintentionally cultivated in the ICT section, affecting social presence through a "technological divide". This appeared to have created a sense of "us" and "them". Students from Country three perceived the others as "just voices" while the other countries had "no faces" to connect to students in Country three. These findings are in agreement with Perry and Southwell (2001) who recognized that technology could both facilitate intercultural interactions as well as reinforce cultural biases. Here are some of the student comments:

Well, the students from [Country three] did not have the same technology during the course and that made a difference. It was O.K. with [Country one and two]; it felt as if we were in the same room. But the small difference of not having them on the big screen was enough to make one feel that there was a difference. (country four)

We never saw them; we were suddenly given a name and were expected to write a paper with that person. We did not even know if it was a boy or a girl because the names are different from ours. (country one)

I was looking forward to this meeting (i.e. onsite) because on the Skype meetings [i.e. lectures in the computer-mediated section] we could not see anyone from the other countries... we just heard voices. (country three) 
These findings confirm Pallof and Pratt (2007) in that "social presence" plays an especially prominent role in blended learning intercultural contexts and needs to be integrated in course design in a way that facilitates rather than hinders. Some students independently explored and utilized open source ICT tools to find ways to create a sense of social presence.

[Referring to a intercultural reaction paper] We used a program called Google. Doc: you can write in it together, in the present. It was as if we were sitting beside each other. (country two)

The onsite meeting appeared to reverse the negative effects of differences in culture, language and technology noted in the ICT section. Students felt that instructors could have arranged more opportunities to enhance intercultural social interactions and wanted to know more about the other countries.

I think for my part...the best chances of getting to know [the others] formally and informally would be during the coffee breaks. Perhaps it could be arranged so we could blend a little more.(country two)

... and have more cooperation between countries, a lot more cooperation between countries. (country one)

\section{Integrating perspectives and importance of content}

In this area the focus group interviews confirmed the results seen the questionnaires. Students are motivated and positive to the content of the multi-institutional course that provided them with expertise and information not available within their HEI. Participants said they had gained an appreciation and deeper understanding of the course content and its practical implications. They talked about different ways of integrating information attained through the course into their prevailing knowledge system.

We should have this course in our own programme, we need courses that give us tools to work with these children...(country four)

Through attending the course students reported constructed knowledge and engaged in analytical thinking that integrated course content into their prevailing knowledge base. This created a new pedagogical paradigm.

We are so happy that we got this chance. As mentioned before this is not included in our regular degree, it is an extra course. I think it complements the others (referring to content in degree programme), I don't see any conflicts. Traditionally one can see some conflicts between the behaviouristic and socio-cultural perspective - which dominates our programme... but it is quite the opposite.... It is a way of thinking which is constructive, creative and it gives one the energy to do something.(country four)

...now we have to like blend it in ...I like it, because this is so specific in the way you observe things and you really try to get to the core of things.. (country one)

Through the case presentations, interactions between the students evolved and they later articulated an appreciation that the knowledge obtained through the course could improve conditions for children in their own countries. Clearly, this led to reflective thinking and personal negotiations concerning practices. These reflections indicate that, in particular, the completing and sharing of the case-based activity prompted enhanced cultural awareness. This is consistent with other findings in the literature (cf. Bransford, 2003; Perry \& Southwell, 2011). As Karlburg 
(2010) points out, global cross-curricular collaboration has the potential to change the way participants perceive and talk about aspects of the world.

In (country three), there is just one system... we can improve it with our knowledge...It could be possible, I think so. I have contacts in (name of government) and I know how difficult it is to change things; you try to tell them about what happens in small villages, in small groups of these people, how they live, what their needs are to make their lives better. (country three)

There are more perspectives when you have an international course like this one. It is natural that one questions things that you have always perceived as being "clear cut"...When others say we do it like this, then you naturally begin to reflect and ask yourself, why do we do it this way? Is it better? (referring to the case assignment) (country four)

Even for the students in country two that had studied some behaviour analysis in their master programme, the content of this course enriched their previous knowledge and provided new insights.

We learned a lot about how the system works. Since we knew some of the subjects from before there was repetition, but it is also good to have a repetition. There are not many people who actually go and investigate the health system. That was really interesting. (country two)

I had an interest in this to begin with (working with children with autism), but I think that if in the future if I would be given the option to work with children with autism, in a private firm, or as a consultant in a company, the experience from this course might actually shift my interests in this direction country two)

\section{Blended learning and pedagogical considerations}

It appears that mixing theoretical readings, lectures, with simulations strengthened student's perception of their own professionalism and understanding of content.

(Referring to the simulation) I have more knowledge and can work better... When I was in practice in my studies I obtained some knowledge so when I saw an example I had had in my own experience, it was easier to understand. (country three)

Part of this course provides inspiration from sources you rarely access; you do not get much of it in theory, principles, and science.... I think it is just basic to learning: you read, you talk, and you need to practice. (country two)

Some participants noted that videoconferencing was more impersonal than face-to -face interaction and that this affected learning. This may have been a result of the language differences and participation routes or could be some students have greater personal need for social presence than others.

What I did notice about my own learning is that it is more difficult to learn with videoconferences [than onsite], so maybe I need the social interaction with the person who talks (country one)

The student's pre-understanding of pedagogical traditions varied and, as Rapoport (2006) contends pedagogical traditions/ methodologies functional in one culture cannot automatically be transferred to another culture. Student responses highlight the importance of support from an onsite facilitator for both content and pedagogical methods, especially when the methods are unfamiliar. 
Before every video conference we spent about an hour discussing issues that were likely to be raised. (country one)

The first reaction paper was the hardest; everyone just left (their studios), and we were supposed to work with someone from another country. (country four)

...with these reaction papers...we got a sheet saying we should write a reaction paper and in (name of country) we have never had a word called a "reaction paper", so the critical (analysis) of a text we had never done before (country one).

Language was an issue discussed from different angles. Some commented on a necessary prerequisite level of English. The joint writing of intercultural reaction papers in the computermediated section highlighted this issue.

My partner was very good. He spoke English perfectly, and we had a good time on Skype. He was a good writer, so that worked very well. I enjoyed that way of working... (country four)

I had to work with a student who did not speak a word of English. I tried to call her on Skype but she would not reply. She was trying to tell me that she actually did not speak English... Well, she tried; her brother was helping her but it really did not work out. He was using a Google translator or something. I tried but...(country two)

\section{The world becomes more open in a positive way}

Participants commented that the multi-institutional blended learning environment course in its entirety opened their world to expertise that they would not otherwise have had contact.

Without the videoconference I would never have had the opportunity to listen to some of the lecturers because they would never have come to ... (country one)

Now I could be face-to-face with the researchers who conduct the studies, and they tell us immediately what the results are ... what the impact is or what they think the impact will be in the future. That was a powerful experience. (country four) (onsite)

There is monotony when you regularly attend classes at your academy or university...but when lecturers come whom you do not see every day...you are attentive, you are watchful, and you learn personally useful information. (country three) (onsite)

Several participants pointed out that international exchanges in the onsite section stimulated them to reflect on similarities and differences between cultures. Some started an intercultural network in order exchange professional knowledge.

I think it is really interesting to meet all these people, because we have really different backgrounds... Now we have kind of started our own network with other countries. (country one)

I wanted to know about the other countries, about their systems, about some of their research, and what has been done. (country three).

The citation below demonstrates a degree of cultural competence that evolved through the onsite interactions with students from another culture.

...interesting, especially with (name of country). They have a quite different system, and it is interesting to hear from them and learn what they are doing. They are developing their culture 
right now. As was said - 20 years ago they belonged to the Soviet Union - and it is happening so very fast. I think it is very exciting to follow what they are doing. (Country four)

\section{Conclusions and future directions}

Universities play an important role preparing professionals to meet the learning and developmental needs of persons with ASD. The course described in this case study was designed to introduce applied behaviour analysis and autism treatment to graduate level students in the Nordic-Baltic region. It was blended and multi-institutional. To this end the course was unique within the region integrating theoretical knowledge and professional skill development activities in an intercultural arena. While students reported high satisfaction with the blended learning elements and access to instructors with high expertise several unforeseen challenges emerged that serve to guide future course design.

While cultural differences with in Nordic-Baltic region might outwardly be perceived as subtle, these differences were accentuated within the ICT section and "cultural divides" were noted to be in the making. Though course instructors had planned for intercultural collaboration in the ICT section through the reaction papers, the resulting effect was quite the opposite than anticipated. Collective projects can set the occasion for expansive learning (Engeström, 1987) but they can also lead to disrupted learning when students are not provided with a clear context for what they are learning and under what conditions they are to learn. For example, in previous research (Roll-Pettersson \& Alai-Rosales, 2009) students all worked within a particular sociopolitical context, shared a common language, and could discuss treatment delivery and procedures with this common platform. Conversely, the students in the present study functioned in a myriad of cultural contexts, some quite different than others. Karlburg (2010) and others have suggested "global citizenship" curricula be part of a liberal arts education. Our experiences here lead us to believe that some amount of preparation in this area could successfully be embedded courses of this nature. For example, Karlburg suggests that a global citizenship curriculum include learning objectives related to identity constructs, ethics and social practice (2010). In this course student learning goals were content specific (ABA and autism), and improving cultural competency was an implicit learning goal embedded in the research project per se rather than as an explicitly written, well-thought through goal to which instructors and students were committed (Karlburg, 2010). It is possible that explicit instructional goals in these areas would allow courses like this to consistently expand aspects of cultural competency for the majority of students. If such goals had been incorporated it is probable that the negative impact of technology, uneven comprehension of English, and differing pedagogical traditions would have been addressed more thoroughly in the planning of the course. In areas of globalization researchers highlight the importance of explicitly addressing cultural competency though the goals themselves might be difficult to evaluate (Karlburg, 2010).

There were also some areas where the uneven access to technologies might have been improved, highlighting the importance of instructors considering potential barriers induced by unequal technology. Future courses would benefit from a more prominent and defined role for the onsite facilitator as a mediator of content, culture, language and varying pedagogic traditions.

Given, the extant literature available on the topics of content, technology and culture as well as our experiences with this course and the student data, we have developed an overview of the primary challenges and possible solutions to blended course design across cultures. Table 1 summarizes challenges described in the literature, encountered in this project, and possible solutions in each of these areas. We hope the variables summarized here will serve as a template for design and implementation of other blended, multi-cultural profession based courses. 
As the world becomes more global, specialised, and research findings play a more prominent role in interventions, it is becoming more difficult for single HEI to meet the academic and instructional expertise required among various professions. This is clearly the case in regard to new fields, such as applied behaviour analysis in the treatment of autism. The implications from this study contributing to a broader academic conversation are that blended learning has the potential to transmit expertise to underserved areas as well as reveal foundations of knowledge and aspects of cultures important to a global society and to individual progress. A caveat, however, is that technology, pedagogy, and language can function as cultural dividers these effects should be taken into consideration.

Table 1: Course design template

\begin{tabular}{|c|c|c|c|}
\hline $\begin{array}{l}\text { Design } \\
\text { Areas }\end{array}$ & $\begin{array}{l}\text { Consideration } \\
\text { Factors }\end{array}$ & Challenges & Suggested amendments \\
\hline $\begin{array}{l}\text { Disciplinary } \\
\text { Content }\end{array}$ & $\begin{array}{l}\text { Student } \\
\text { prerequisites }\end{array}$ & $\begin{array}{l}\text { Uneven } \\
\text { knowledge }\end{array}$ & $\begin{array}{l}\text { Adjust learning activities and outcomes to pre- } \\
\text { level understanding; Onsite facilitators provide } \\
\text { compensatory support for disparities. }\end{array}$ \\
\hline \multirow[t]{2}{*}{$\begin{array}{l}\text { Instructional } \\
\text { Delivery }\end{array}$} & $\begin{array}{l}\text { Technical } \\
\text { support }\end{array}$ & $\begin{array}{l}\text { Uneven technical } \\
\text { resources and } \\
\text { expertise }\end{array}$ & $\begin{array}{l}\text { Assessment of technical resources within each } \\
\text { HEI before course starts; Cross cultural } \\
\text { technical teams, help desk and consideration of } \\
\text { alternate pathways to compensate for } \\
\text { technological variations. }\end{array}$ \\
\hline & $\begin{array}{l}\text { Learning } \\
\text { activities \& } \\
\text { social presence }\end{array}$ & $\begin{array}{l}\text { Logistical } \\
\text { understanding }\end{array}$ & $\begin{array}{l}\text { Clear specification for each learning activity } \\
\text { regarding "who" is to be involved, "what" } \\
\text { technology is required, and methods to } \\
\text { alleviate potential threats to social presence. }\end{array}$ \\
\hline \multirow[t]{4}{*}{$\begin{array}{l}\text { Cultural } \\
\text { Context }\end{array}$} & Language & $\begin{array}{l}\text { Uneven } \\
\text { comprehension } \\
\text { and expression }\end{array}$ & $\begin{array}{l}\text { Onsite facilitator mediation and/or basic } \\
\text { requirement of common language; } \\
\text { Consideration of "why" and "when" of } \\
\text { intercultural activities }\end{array}$ \\
\hline & $\begin{array}{l}\text { Pedagogical } \\
\text { methods }\end{array}$ & $\begin{array}{l}\text { Differing } \\
\text { pedagogical } \\
\text { traditions }\end{array}$ & $\begin{array}{l}\text { Open pre-course instructor dialogue regarding } \\
\text { similarities and differences and consideration } \\
\text { of pedagogical methods students have } \\
\text { experienced. Dialogue with students } \\
\text { concerning methods and skills appropriate to } \\
\text { discipline but unfamiliar in some cultural } \\
\text { pedagogies (e.g., guided design). }\end{array}$ \\
\hline & $\begin{array}{l}\text { Cultural } \\
\text { competency }\end{array}$ & $\begin{array}{l}\text { Prejudice } \\
\text { Insensitivity } \\
\text { Intolerance } \\
\text { Indifference }\end{array}$ & $\begin{array}{l}\text { Inclusion of explicit learning outcomes that } \\
\text { address cultural competency; Planned learning } \\
\text { activities in accordance; Dialogue with students } \\
\text { concerning values and skills about how culture } \\
\text { may affect behaviour (e.g., global citizenship); }\end{array}$ \\
\hline & $\begin{array}{l}\text { Assessment of } \\
\text { cultural } \\
\text { competence }\end{array}$ & $\begin{array}{l}\text { Difficult to } \\
\text { measure }\end{array}$ & $\begin{array}{l}\text { Identify on site facilitators who have knowledge } \\
\text { concerning course content AND working across } \\
\text { cultures; Evaluation by both students and } \\
\text { instructors concerning cultural competence. }\end{array}$ \\
\hline
\end{tabular}




\section{References}

1. Ala'i-Rosales, S.; Roll-Petterson, L.; Pinkelman, S.; Cihon, T. (2010). Higher Education Programs in Applied Behavior Analysis and Autism: Emerging Opportunities. In European Journal of Behavior Analysis, 11, (pp. 207-216)

2. American Psychiatric Association (2000). Diagnostic and statistical manual of mental disorders, (4th ed., text rev.). Washington, DC:

3. Baer, D.M.; Wolf, M.M.; Risley, T.R. (1968). Some current dimensions of applied behaviour analysis. In Journal of Applied Behavior Analysis, 1, (pp. 91-97)

4. Behavior Analysis Certification Board (2014). Autism Practice Guidelines - Health Plan Coverage of Applied Behavior Analysis Treatment for Autism Spectrum Disorder. Retrieved from http://www.bacb.com/Downloadfiles/ABA_Guidelines_for_ASD.pdf (January 7, 2014)

5. Bonk, C.J. and Graham, C.R. (2006). The Handbook of Blended Learning; Global Perspectives, Local Designs. Pfeiffer, An imprint of Wiley. San Francisco:

6. Bransford, J. (2003). Some special features of this special issue: Core values and possible next steps. In Mind, Culture, and Activity, 10(1), (pp. 80-85)

7. Corbin, J.; Strauss, A. (2008). Basics of Qualitative Research, $3^{\text {rd }}$ edition. Sage P. Los Angles

8. Cronjé, J.C. (2009). Qualitative Assessment across Language Barriers: An Action Research Study. In Educational Technology \& Society, 12(2), (pp. 69-85)

9. Dey, I. (2012). Grounded Theory. In C. Seale, G. Gobo, J. Gubrium, D. Silverman (eds.), Qualitative Research Practice, (pp. 80-95). Sage Publications. Thousand Oakes, California.

10. Durkin, K. (2008). The Adaptation of East Asian Masters Students to Western Norms of Critical Thinking and Argumentation in the UK. In Intercultural Education, 19(1), (pp. 15-27)

11. Engeström, Y. (1987). Learning by expanding: An activity-theoretical approach to development research. Orienta-Konsultit. Helsinki

12. Green, G. (2010). Training Practitioners to Evaluate Evidence about Interventions. In European Journal of Behavior Analysis, 11, (pp. 223-228)

13. Grey, I.M.; Honan, R.; McClean, M.; Daly, M. (2005). Evaluating the Effectiveness of Teacher Training in Applied Behaviour Analysis. In Journal of Intellectual Disabilities, 9(3), (pp. 209-27)

14. Holley, D. and Oliver, M. (2010). Student engagement and blended learning: portraits of risk. In Computers \& Education, 54, (pp. 693-700), Elsevier Publishing, DOI information: 10.1016/j.compedu.2009.08.035, ISSN: 0360-1315

15. Karlburg, M. (2010). Education for interdependence: The University and the global citizen. In The Global Studies Journal, 3, (pp. 129-138)

16. Kim, K-J.; Bonk, C.J. (2006). The Future of Online Teaching and Learning in Higher Education: The Survey Says. In EDUCAUSE, 29. (pp. 22-30)

17. Mavroidis I.; Anthi Karatrantou, A.; Koutsouba, M.; Giossos, Y.; Papadakis, S. (2013). Technology Acceptance and Social Presence in Distance Education - A Case Study on the Use of Teleconference at a Postgraduate Course of the Hellenic Open University. In European Journal of Open and Distance E-Learning, http:/ / www.eurodl.org/index.php?article $=590$ 
18. Muntean, V.; Calinici, T.; Tigan, S.; Fors, U.G.H. (2013). Language, Culture and International Exchange of Virtual Patient. In BMC Medical Education, 13, (pp. 21) http://www.biomedcentral.com/1472-6920/13/21

19. National Autism Center (2009). National Standards Project Report. (Retrieved November 21, 2013 from: http://www.nationalautismcenter.org/affiliates/

20. National Research Council, Committee on Educational Interventions for Children with Autism, Division of Behavioral and Social Sciences and Education. (2001). Educating Children with Autism. National Academy Press. Washington DC:

21. Odom, S.L.; Collet-Klingenberg, L.; Rogers, S.J.; and Hatton, D.D. (2010). Evidence-Based Practices in Interventions for Children and Youth with Autism Spectrum Disorders. In Preventing School Failure, 54(4), (pp. 275-82)

22. Palloff, R.M. and Pratt, K. (2007). Building Online Learning Communities: Effective Strategies for the Virtual Classroom. John Wiley \& Sons. San Francisco CA:

23. Perry, L.B. and Southwell, L. (2011). Developing Intercultural Understanding and Skills: Models and Approaches. In Intercultural Education, 22(6), (pp. 453-66)

24. Pombo, L.; Loureiro, M. J.; Moreira, A. (2010). Assessing collaborative work in a higher education blended learning context: Strategies and students' perceptions. In Educational Media International, 47(3), (pp. 217-229)

25. Rapoport, A. (2006). Beware of Greeks? Some Aspects of Intercultural Communication in International Training Programs for Educators. In Intercultural Education, 17(2), (pp. 179-194)

26. Reyen, A. (2012). Ethical Issues. In C. Seale, G. Gobo, J. Gubrium, D. Silverman (eds.), Qualitative Research Practice, (pp. 218-235). Sage Publications. Thousand Oakes, California:

27. Roll-Pettersson, L.; Alai-Rosales, S (2009). Using Blended and Guided Technologies in a University Course for Scientist-practitioners: Teaching Applied Behavior Analysis to Autism Professionals. In Journal of Intellectual Disabilities, 13(2), (pp. 113-42)

28. Roll-Pettersson, L.; Alai-Rosales, S.; Keenan, M. and Dillenburger, K. (2010). Teaching and learning technologies in higher education: Applied behaviour analysis and autism; "Necessity is the mother of invention". In European Journal of Behavior Analysis, 11(2), (pp. 247-259). http://www.ejoba.org/PDF/2010_2/RollPettersson_AlaiRosales_Keenan_Dillenburger_20 10.pdf

29. Scheuermann, B.; Webber, J.; Boutot, E.; Goodwin, M. (2003). Problems with Personnel Preparation in Autism Spectrum Disorders. In Focus on Autism and other Developmental Disabilities, 18(3), (pp. 197-06)

30. Simpson. R.L.; Mundschenk, N.A.; Heflen, L.J. (2011). Issues, Policies, and Recommendations for Improving the Education of Learners with Autism Spectrum Disorders. In Journal of Disability Policy Studies, 22, (pp. 3-17)

31. Stacey, E. and Gerbic, P. (2007). Teaching for blended learning - Research perspectives from on-campus and distance students. In Education and Information Technologies, 12(3), (pp. 165-74)

32. Stewart, D.W.; Shamdasani, P.N. \& Rook, D.W. (2007). Focus Groups; Theory and Practice. Sage Publications. London

33. Sulzer-Azeroff, B.; Fleming, R.; Tupa, M.; Bass, R.; Hamad, C. (2008). Choosing Objectives for a Distance Learning Behavioral Intervention in Autism Curriculum. In Focus on Autism and Other Developmental Disabilities, 23(1), (pp. 29-36) 
34. Trivette, C.; Dunst, C.J., Hamby, D.W.; O’Herin, C.E. (2009). Characteristics and Consequences of Adult Learning Methods and Strategies. In Winterberry Research, 2(2), (pp. 1 33)

35. Weiss, M.J. and Shook, G.L. (2010). Resources on training requirements for applied behavior analysts: The Behavior Analyst Certification Board and the Autism Special Interest Group Guidelines. In European Journal of Behavior Analysis, 11(2), (pp. 217-222) http://www.ejoba.org/PDF/2010_2/Weiss_Shook_2010.pdf

36. Yell, M.L.; Drasgow, E.; Lowrey, K.A. (2005). No Child Left Behind and Students with Autism Spectrum Disorders. In Focus on Autism and Other Developmental Disabilities, 20(3), (pp. 130-139)

37. Zhu, C.; Valcke, M.; Schellens, T. (2009). A Cross-cultural Study of Online Collaborative Learning. In Multicultural Education \& Technology Journal, 3(1), (pp. 33-46)

\section{Acknowledgements}

We would like to thank Nordplus Higher education for providing the economical means to meet onsite and Christine Nord, University of North Texas, for editing. 